\title{
EFFECT OF TECHNOLOGICAL PARAMETERS ON THE SURFACE ROUGHNESS OF ALUMINIUM ALLOYS AFTER TURNING
}

\author{
Ireneusz Zagórski ${ }^{1}$, Tomasz Warda ${ }^{1}$ \\ 1 Department of Production Engineering, Faculty of Mechanical Engineering, Lublin University of Technology, \\ Nadbystrzycka 36, 20-618 Lublin, Poland, e-mail: i.zagorski@pollub.pl
}

Received: 2018.02 .23

Accepted: 2018.04.22

Published: 2018.06.01

\begin{abstract}
The paper analyses the effect of technological parameters of turning ( $\mathrm{V}_{c}$ and $\mathrm{f}$ ) on the 2D surface roughness parameters of aluminium alloys. Turning was carried out with SVJBL 2525 M11 shank tool, with VCGT 110302FN-25P insert, dedicated for machining light alloys. Three aluminium alloy types were examined in the study: 7075 , 2024, 6082. The present study is focused on selected 2D surface texture parameters, and concludes that feed exerts considerable impact on the surface quality. Simultaneously, the findings of the study indicate that from the technological perspective the change of cutting speed $v_{c}$ does not impact the quality of the machined surface.
\end{abstract}

Keywords: aluminium alloys, turning, surface roughness.

\section{INTRODUCTION}

Aluminium alloys constitute a modern structural material, which finds application in various branches of the machinery industry. Their wide applicability results from favourable properties and low density. Major physical properties of aluminium alloys relevant from the viewpoint of machining are: low Young's module, high thermal expansion and conductivity [18].

Machinability of aluminium alloys is dependent on their chemical composition and their (thermal-treatment dependent) structure. The silicon $(\mathrm{Si})$ content in $\mathrm{Al}$ alloys cannot exceed $10 \%$, as beyond this point the machinability of the alloy is diminished due to considerable tool wear. Surface roughness may be altered by several factors: type of workpiece material, tool quality, tool coating, technological parameters. Among technological parameters of milling this is the value of feed $\mathrm{f}$ that affects the surface roughness to the greatest extent, cutting speed $\mathrm{v}_{\mathrm{c}}$ is less relevant, whereas the axial depth of cut $\mathrm{a}_{\mathrm{p}}$ constitutes the least important element [9]. Aluminium alloys which yield to plastic working are subject to the general rule applied to subtractive machining, i.e. the higher the strength and hardness of an alloy, the better the quality of machined surface. In aluminium cast alloys it is the microstructure of a given alloy that plays a pivotal role. Hard elements in soft matrix may be torn or cleft out during machining, which in turn leads to decreasing the surface quality. In turning of aluminium alloys, except for suitable tool geometry $\left(\gamma \leq 30^{\circ}\right.$, $\alpha \leq 10^{\circ}$ ), it is critical to control chip breaking or curling. The latter is possible when applying a dry machining with cool air, using the system devised by Ceterazit (Austria), which by blowing compressed air enables dry machining of $\mathrm{Al}$ alloys.

An aluminium alloy $\mathrm{AlMg} 1 \mathrm{Si}$, which is ductile, hard and subjected to forge rolling to impart strength, is an example of a material which demonstrates poor machinability. In turning with carbide inserts controlled breaking or curling of chips may not occur. The effectiveness of the process may be improved by applying a polycrystalline diamond tool (PCD), chip breaker plate or bevel with a negative tool rake angle $\gamma$, which cause that the chip is broken at shorter intervals, hence their evacuation from the cutting zone is 
facilitated [11]. Tool manufacturers [19] suggest that $\mathrm{Al}$ alloys should be machined at the cutting speed $v_{c} \geq 2500 \mathrm{~m} / \mathrm{min}$. However, recent surge in manufacturing process efficiency and developments in the field of high performance cutting exert considerable and growing pressure on the quality and performance of cutting tools.

The suitability of a cutting tool for a particular application may be always expressed by whether the tool provides good workpiece surface finish. Frequently, the condition of the surface after machining is final and has a direct impact on the performance of a given element. Therefore, machining processes determine the desired geometry of work surfaces and of the surface layer of machinery and devices. In certain conditions it may be impossible to carry out machining operations without the use of cutting fluid, hence it is critical to specify optimal cutting conditions considering the amount and method of supplying the fluid. Increasing flow of fluid may improve surface roughness properties of a workpiece [2]. High-speed CNC machine tools ascertain that the surface of the workpiece is within the standards of dimensional and shape accuracy. Owing to incessant progress of tool materials, tool cutting edge inserts, and optimisation of tool coatings contribute to improving quality of the surface layer subjected to turning $[6,8]$. In addition, adherence to rules of good metrological practice is of great importance at an every stage of measurement, from the selection of measuring instruments, through checking and calibration of profilometer, to the actual measurement and analysis of results to ensure correct and credible measurement of surface topography [14].

Literature in the field of surface roughness analysis after machining predominantly deals with 2D surface profile analysis, due to attainable cutting speeds (determined by $\mathrm{d}_{\max }$ and $\mathrm{n}_{\max }$ ). It has been shown that in machining of aluminium alloy 7075 it possible to apply high cutting speeds $\mathrm{v}_{c}$ (up to $1700 \mathrm{~m} / \mathrm{min}$ and higher) without compromising the quality of the machined surface. Surface roughness parameters that are frequently under analysis in research papers, $\mathrm{Ra}$ and $\mathrm{Rz}$, do not exceed the level of approximately $2 \mu \mathrm{m}$ and $10 \mu \mathrm{m}$ at any cutting speed. Increase in feed results in linear increase in the surface roughness parameters, which is in accordance with the common theoretical relationship expressed by $\mathrm{Rz}_{\mathrm{t}}=\mathrm{f}^{2} / 8 \mathrm{r}_{\varepsilon}$ [18]. It may be inferred that surface quality will improve when cutting is carried out with a suitable PCD tool.
A great deal of the body of literature is devoted to the issues of selection and optimisation of turning parameters with a view to improving the economic and technological effects of machining. In this respect, researchers indicate the potential of polycrystalline diamond tools (PCD) in e.g. machining the surface of pistons, which are made of Al cast eutectic and hypereutectic Al-Si alloy. Hard and abrasive Si particles may contribute to significant tool wear. In the analysed case, the optimum parameters for the machine cutting were established at $\mathrm{v}_{\mathrm{c}}=610 \mathrm{~m} / \mathrm{min}, \mathrm{a}_{\mathrm{p}} \leq 1 \mathrm{~mm}$ [17].

Built-up edge (BUE) and tool wear are parameters that are in focus of numerous analyses of turning with coated cemented carbide tools (Kennametal SNG 433-K68, $\gamma=5^{\circ}, \chi_{\mathrm{r}}=15^{\circ}$, $\left.\lambda_{\mathrm{s}}=5^{\circ}\right)$. Our tests evaluated machinability of three aluminium alloys: 2024, 6061, 7075; and employed maximum cutting speed $\mathrm{v}_{\mathrm{c}}=245 \mathrm{~m} / \mathrm{min}$. In experimental observations typical tool-chip interaction zones were noted; these are defined by different friction conditions, and are referred to as seizure (I and II) and sliding [1]. The mutual relation between the occurrence of built-up layer and the quality of machined surface has been the subject of investigations in the literature. One analysis was devoted to dry machining of UNS A9 2024 (Al-Cu) and UNS A9 7050 (Al-Zn), the maximum cutting speed amounted to $\mathrm{v}_{\mathrm{c}}=170 \mathrm{~m} /$ $\mathrm{min}$, and the process was carried out with the cutting tool equipped with coated cemented carbide inserts (SECO, DCMT11T308-F2 HX), with and without TiN coating. Consequently, it was observed that $\mathrm{Ra}$ is inseparably connected with the machined length $\mathrm{L}(\leq 175 \mathrm{~mm})$, i.e. with increasing $\mathrm{L}$, the value of $\mathrm{Ra}$ decreased. The latter showed a similar reaction when BUE increased [4]. Other frequently analysed parameters include: axial depth of cut, feed, cutting speed or corner radius. In dry machining of 2030-T4 alloy the highest impact on the surface quality exerted feed and axial depth of cut [7].

Numerous studies have proven that surface topography is critical to the performance of machine elements. There exist practical methods for the improvement of technological and practical quality of a workpiece by means of finishing operations. This discussion was based on both 2D surface roughness parameters and stereometric properties of surface roughness $3 \mathrm{D}$, which determine the applicability of turning. Dimensional tolerance and shape accuracy are both of great importance in engineering design, however, the 
relationship between the performance of surface and its geometry, constituting an element of geometrical structure of the surface (GSS), is valued as highly. Geometrical structure of the surface affects numerous performance related properties, e.g.: fatigue strength, wear strength, corrosion resistance, contact strength, resistance of flow, water-tightness of joints. Metrology of stereometric properties of surface roughness enables prediction of surface behaviour of a given element, or in cooperation with other parts and the degree to which a given element fulfils the designed functions in operation. According to Polish technical nomenclature, this combines the technological and performance quality of an element [3].

A number of studies in the recent years have undertaken the problem of modelling the machining process with the application of suitable models (mathematical analytic methods) and computer systems (Statistica, Matlab) which employ e.g. artificial neural networks when the process is highly complicated and it is considerably difficult to apply suitable mathematical formulas $[5,13]$. Nevertheless, correct formulation of models requires detailed input data, which will provide an accurate description of an analysed process.

Turning processes rely to a considerable extent on error compensation of CNC lathe probes, as it plays a decisive role in dimensional accuracy of a workpiece. Particular procedures of compensation may be matched with given tolerance classes, especially for elements produced in classes IT5 and IT6. The compensation procedure may contribute to reducing tool wear (of tools applied in the compensation procedure), particularly when the tools are used in the production plan after the measurements [16].

$\mathrm{CNC}$ lathes find application when workpieces of intricate geometry are machined. Their characteristic technological flexibility makes it possible to adjust the machine easily and quickly to a subsequent technological task. Even machining complicated profiles of solids of revolution does

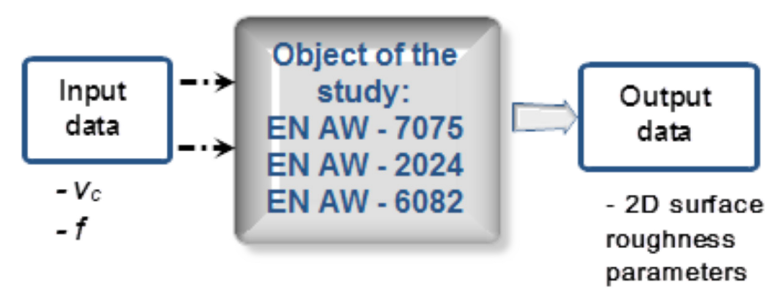

Fig. 1. General plan and object of the study not require applying additional instrumentation. Constant modernisation of control systems, developments in the design of machine tools and improvements in the lathe modules of CAM software all contribute to extending the capabilities of CNC lathes in manufacturing of an ever-wider range of products [10].

\section{METHODOLOGY AND AIM OF STUDY}

Three types of aluminium alloys for plastic working analysed in the study belong to the group of precipitation hardened alloys. They represent three alloy groups: group 2xxx (Al-Cu and Al$\mathrm{Cu}-\mathrm{Mg}$ alloys), group 6xxx (Al-Mg-Si alloys) and group 7xxx (Al-Zn-Mg and Al-Zn-Mg-Cu alloys). The analysed types of alloys (7075-T6511, 2024-T3511, 6082-T651) and the general plan of the study are shown in Figure 1.

The process of turning, to which each of the alloys was subjected in the study, was performed on the DMG MORI CTX450 CNC turning machine with Sinumerik 840D digital NC system. Turning was carried out with SVJBL 2525 M11 shank tool with VCGT 110302FN-25P insert of corner radius $r_{\varepsilon}=2 \mathrm{~mm}$, dedicated for machining light alloys. Machining process was conducted at constant depth of cut $a_{p}=1 \mathrm{~mm}$, and changing range of other technological parameters: $\mathrm{f}=0.05 \div 0.15 \mathrm{~mm} / \mathrm{rev}$., $\mathrm{v}_{\mathrm{c}}=700 \div 900 \mathrm{~m} / \mathrm{min}$. Cutting fluid was supplied throughout the cutting process. The machined length was equal to $\mathrm{L}=$ $15 \mathrm{~mm}$. Surface roughness was measured by means of Hommel Tester T1000 profilograph, and each measurement was repeated ten times. The study analysed selected 2D surface roughness parameters detailed in the standard PN-EN ISO 4287:1999 [20]. The primary objective of the study was to conduct comparative analysis of different type aluminium alloys within the same material group, and yet of distinct mechanical and physical properties.

\section{TEST RESULTS AND ANALYSIS}

Bar charts in Figures $2 \div 7$ show changes of surface roughness parameters ( $R a, R z, R t, R p$, RSm) as a results of change of cutting speed $v_{c}$ and feed $\mathrm{f}$.

\section{Change of cutting speed $v_{c}$}

Figure 2 shows the response of $\mathrm{Ra}$ and $\mathrm{Rz}$ surface roughness parameters to the change of 

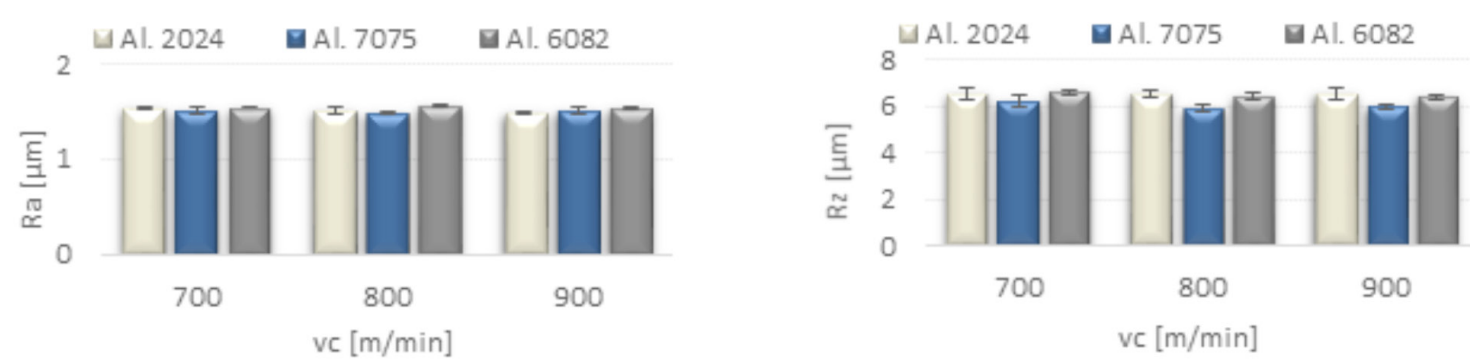

Fig. 2. The effect of cutting speed $v_{c}$ change on surface roughness parameters:

a) $\mathrm{Ra}, \mathrm{b}) \mathrm{Rz}\left(\mathrm{f}=0.11 \mathrm{~mm} / \mathrm{rev} ., \mathrm{a}_{\mathrm{p}}=1 \mathrm{~mm}\right)$
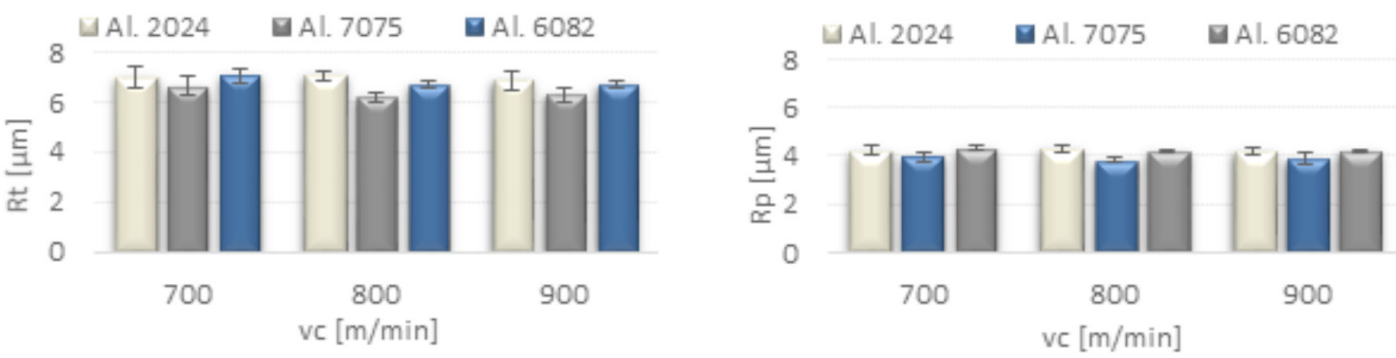

Fig. 3. The effect of cutting speed $v_{c}$ change on surface roughness parameters:

a) Rt, b) $R p\left(f=0.11 \mathrm{~mm} /\right.$ rev., $\left.a_{p}=1 \mathrm{~mm}\right)$

cutting speed $\mathrm{v}_{\mathrm{c}}$. Figure 2 indicates that $\mathrm{Ra}$ and $\mathrm{Rz}$ are manifest negligible change at different cutting speeds, and the recorded values remain with the limit of $\mathrm{Ra} \approx 1.5 \mu \mathrm{m}$ and $\mathrm{Rz} \approx 5.9-6.5 \mu \mathrm{m}$. Slightly lower values of $\mathrm{Rz}$ were observed in 7075 alloy $(5.89-6.23 \mu \mathrm{m})$. It may be considered that the insignificant changes in the $\mathrm{Ra}$ and $\mathrm{Rz}$ are irrelevant from the perspective of technology. In order to evaluate the significance of differences suitable relevance tests should be conducted (verification of the hypothesis of equality of variances and of average). It may be that increasing the cutting speed, and consequently the efficiency of machining, will not result in the decrease of final surface quality.

Figure 3 shows the response of Rt and Rp surface roughness parameters to the change of

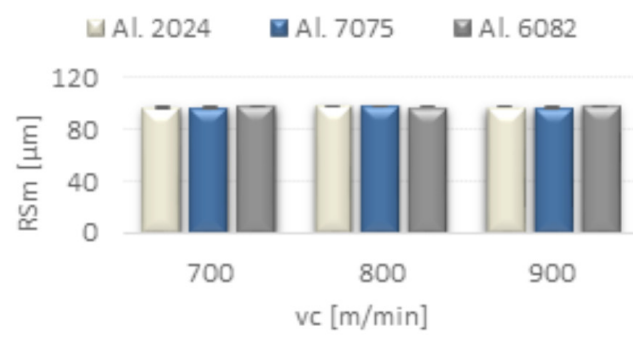

Fig. 4. The effect of cutting speed $v_{c}$ change on RSm surface roughness parameter $\left(\mathrm{f}=0.11 \mathrm{~mm} / \mathrm{rev} ., \mathrm{a}_{\mathrm{p}}=1 \mathrm{~mm}\right)$ cutting speed $\mathrm{v}_{\mathrm{c}}$. It was concluded that for $\mathrm{Rt}$ and $\mathrm{Rp}$ parameters, the change expressed in numeric values was similar, regardless of change of cutting speed $\mathrm{v}_{\mathrm{c}}$. The value of Rt was within approximately $6.2-7 \mu \mathrm{m}$, whereas $\mathrm{Rp}=3.8-4.3 \mu \mathrm{m}$. In the case of the former parameter, its highest values were recorded for 2024 alloy.

Figure 4 shows the response of RSm surface roughness parameter to the change of cutting speed $v_{c}$. We shows that the change of cutting speed $v_{c}$ in the analysed range does not affect the average value of RSm parameter, which remains at a constant $100 \mu \mathrm{m}$, throughout the range of cutting speeds.

\section{Change of feed $f$}

Figure 5 shows the response of $\mathrm{Ra}$ and $\mathrm{Rz}$ surface roughness parameters to the change of feed $f$. Distinct reaction of $\mathrm{Ra}$ and $\mathrm{Rz}$ parameters to the change of feed was observed. Their values rise with the increase in $\mathrm{f}$, which confirms theoretical knowledge. The values of the parameters in question are: $\mathrm{Ra} \approx 0.3-3.1 \mu \mathrm{m}$ and $\mathrm{Rz} \approx 2.1-14 \mu \mathrm{m}$. As in the case with the change of cutting speed $\mathrm{v}_{\mathrm{c}}$, slightly lower values of Rz are observed for 7075 alloy $(2.1-12.8 \mu \mathrm{m})$.

Figure 6 shows the response of Rt and Rp surface roughness parameters to the change of feed $f$. 

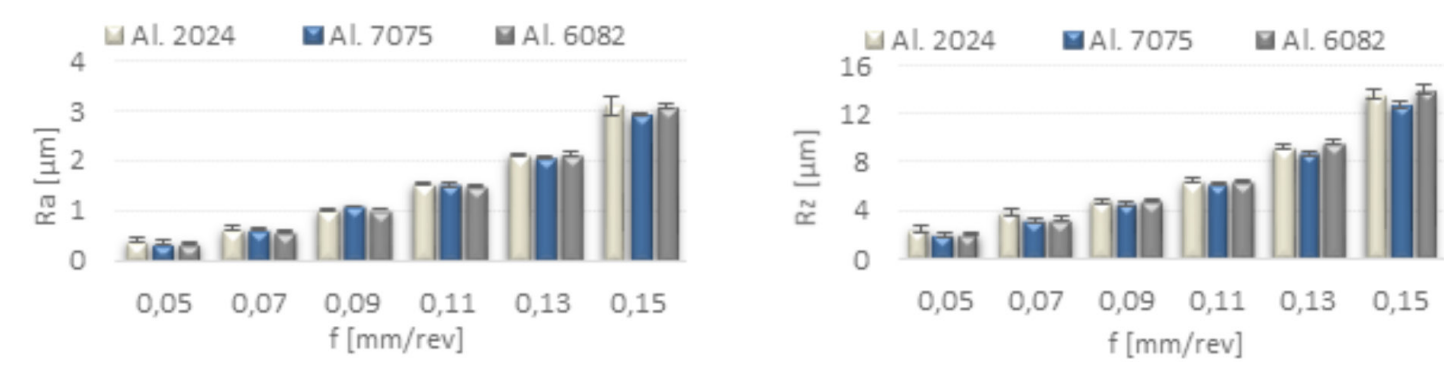

Fig. 5. The effect of feed change on surface roughness parameters: a) Ra, b) $R z\left(v_{c}=800 \mathrm{~m} / \mathrm{min}, a_{p}=1 \mathrm{~mm}\right)$
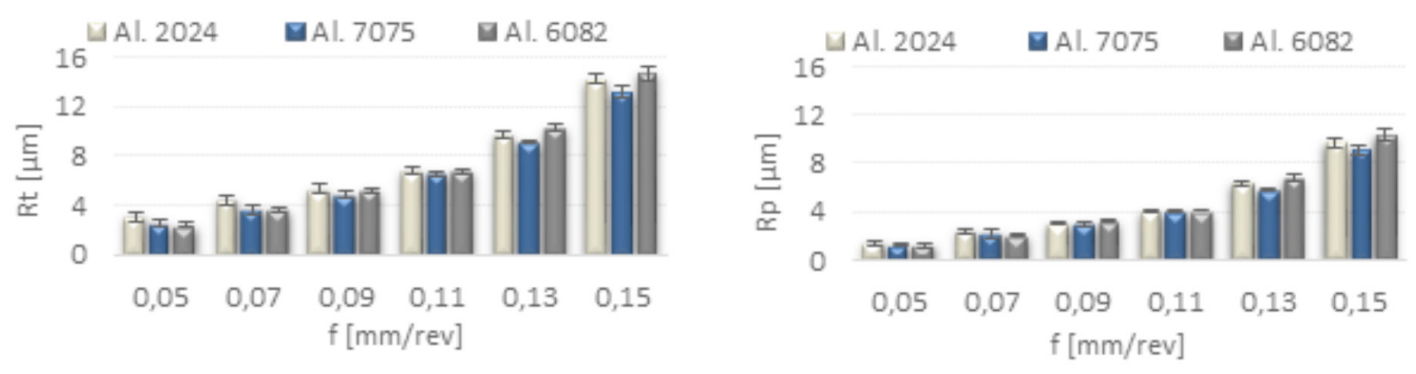

Fig. 6. The effect of feed change on surface roughness parameters: a) Rt, b) $R p\left(v_{c}=800 \mathrm{~m} / \mathrm{min}, a_{p}=1 \mathrm{~mm}\right)$

We shows that Rt and Rp react strongly to the change in feed $f$. Their average values increase with the increase in feed and amount to: Rt $=2.4-14.7 \mu \mathrm{m}$ and $\mathrm{Rp}=1.2-10.3 \mu \mathrm{m}$. For alloy 7075 , both parameters demonstrate slightly lower average values.

Figure 7 shows the response of RSm surface roughness parameter to the change of feed $\mathrm{f}$. It was observed that increased values of the standard deviation for the RSm surface roughness parameter appear for the range of feed $\mathrm{f}=0.05$ $0.07 \mathrm{~mm} / \mathrm{rev}$. From lower scatter of the parameter values we may infer a better stability of the process (lower standard deviation as a measure of the scatter of results). For the stable range of feed $\mathrm{f}=0.09-0.15 \mathrm{~mm} / \mathrm{rev}$. the average value of $\mathrm{RSm}$ was within approximately $80-130 \mu \mathrm{m}$.

\section{CONCLUSIONS}

Aluminium alloys analysed in this study belong to a group of precipitation hardened alloys for plastic working. These types of alloys represent three groups of heat-hardened alloys.

The analysis of cutting parameters for the represented types of aluminium alloys indicates the critical role of correct selection of technological parameters of cutting. The tests and measurements performed in the present study may be concluded by the following general observations:
- The results of the study indicate that there were no significant differences between the quality of surface of three analysed alloys, despite different mechanical parameters of alloys in question.

- Cutting speed $\mathrm{v}_{\mathrm{c}}$ at constant feed $\mathrm{f}$ does not exert a considerable effect on the surface roughness parameters.

- Increasing feed $\mathrm{f}$ results in a significant increase in the surface roughness parameters, due to increased surface profile.

- High cutting speeds $\left(v_{\mathrm{c}} \leq 900 \mathrm{~m} / \mathrm{min}\right)$ may be employed without compromising the quality of machined surface.

- All three analysed aluminium alloys manifest similar average surface roughness parameters after turning.

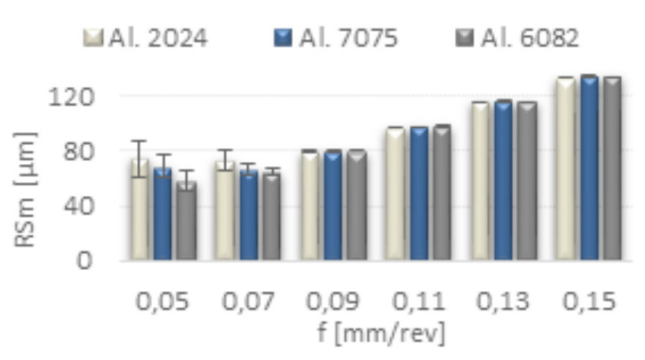

Fig. 7. The effect of feed change on RSm surface roughness parameter $\left(v_{c}=800 \mathrm{~m} / \mathrm{min}, \mathrm{a}_{\mathrm{p}}=1 \mathrm{~mm}\right)$ 
An in-depth analysis of the effect of technological parameters of turning on particular parameters of surface roughness should include statistical analysis and analysis of 3D surface roughness parameters.

\section{REFERENCES}

1. Dursun S.K., Shivakumar R.: Observations of the tool-chip boundary conditions in turning of aluminum alloys. Wear, 262, 2007, 889-904.

2. Feldshtein E., Józwik J., Legutko S.: The influence of the conditions of emulsion mist formation on the surface roughness of AISI 1045 steel after finish turning. Advances in Science and Technology Research Journal, 10, 30, 2016, 144-149.

3. Grzesik W.: Effect of the machine parts surface topography features on the machine service. Mechanik, 8-9, 2015, 587 $\div 593$.

4. Gómez-Parra A., Álvarez-Alcón M., Salguero J., Batista M., Marcos M. Analysis of the evolution of the Built-Up Edge and Built-Up Layer formation mechanisms in the dry turning of aeronautical aluminium alloys. Wear, 302, 1-2, 2013, 1209-1218.

5. Józwik J.: Modeling of workpieces deflections in turning process. Advances in Science and Technology, 8, 2011, 183-191.

6. Kamieńska-Krzowska B., Kłonica M.: The role of surface topography measurement strategy on the evaluation of selected roughness parameters. Mechanik, 8-9, 2014, 138-145.

7. Kilic D.S., Raman S.: Observations of the toolchip boundary conditions in turning of aluminum alloys. Wear, 262, 7-8, 2007, 889-904.

8. Kłonica M., Kuczmaszewski J.: Analysis of the process of forming the chip in the process of turning AW7075 aluminum alloy. Mechanik, 10, 2016, 1382-1383.

9. Kuczmaszewski J., Pieśko P.: Wear of milling cutters resulting from high silicon aluminium alloy cast AlSi21CuNi machining. Eksploatacja i Nieza- wodnosc - Maintenance and Reliability. 16, 1, 2014, 37-41.

10. Kwaczyński W., Filipowicz K.: Innovations in the use of CNC lathes. Mechanik, 8-9, 2016, 1206-1207.

11. Oczoś K.E.: Doskonalenie procesów kształtowania ubytkowego stopów aluminium. Mechanik, 3-4, 2009, 153-163, 249-256.

12. Sedlacek M., Podgornik B., Vizitin J.: Influence of surface preparation on roughness parameters, friction and wear. Wear, 266, 2009, 482-487.

13. Świć, A., Gola, A., Wołos, D., Opielak M.: Microgeometry Surface Modelling in the Process of Low-Rigidity Elastic-Deformable Shafts Turning. Iranian Journal of Science And Technology-Transactions of Mechanical Engineering, 2016, 1-9.

14. Świderski J., Dobrowolski T.: The principles of good practice for the measurement of surface roughness after a very accurate turning. Mechanik, 8-9, 2016, 1140-1141.

15. Torres A., Puertas I., Luis C.J.: Surface Roughness Analysis on the Dry Turning of an Al-Cu Alloy. Procedia Engineering, 132, 2015, 537-544.

16. Włodarczyk M. The influence of the coordinate correction procedure of measuring probe dedicated lathe CTX 450 on the dimensional accuracy. Mechanik, 10, 2016, 1348-1349.

17. Wojciechowski S., Lisiak P., Twardowski P.: Optimization of cutting parameters for the longitudinal turning of combustion engines' pistons. Mechanik, 8-9, 2016, 1022-1023.

18. Zagórski I., Warda T., Włodarczyk M.: The influence of technological parameters on selected surface roughness parameters during aluminum 7075 alloys turning. Mechanik, 8-9 2016, 1060-1061.

19. http://www.sandvik.coromant.com/pl (access: 17.05.2016).

20.PN-EN ISO 4287:1999. (ISO 4287:1997. Geometrical Product Specifications (GPS) - Surface texture: Profile method - Terms, definitions and surface texture parameters). Struktura geometryczna powierzchni: metoda profilowa. 